\title{
O passado recente da educação física no contexto luso-brasileiro: uma nova auto-
}

\section{compreensão}

The recent past of physical education in the Portuguese-Brazilian context: a new self-understanding El pasado reciente de la educación física en el contexto portugués-brasileño: una nueva autocomprensión

Carlos Eduardo Rafael de Andrade Ferrari ORCID: https://orcid.org/0000-0001-8671-7448 Universidade do Porto, Portugal E-mail: ceraferrari@yahoo.com.br

Rafael Mocarzel

ORCID: https://orcid.org/0000-0001-9480-826X Universidade Federal do Rio de Janeiro, Brasil Universidade de Vassouras, Brasil Universidade do Porto, Portugal E-mail: professormocarzel@gmail.com Estêvão Rios Monteiro ORCID: https://orcid.org/0000-0003-1866-553X Universidade Federal do Rio de Janeiro, Brasil Centro universitário Augusto Motta, Brasil Instituto Brasileiro de Medicina de Reabilitação, Brasil E-mail: profestevaomonteiro@gmail.com

Amândio Braga dos Santos Graça ORCID: https://orcid.org/0000-0003-1539-4201 Universidade do Porto, Portugal E-mail: agraca@fade.up.pt

Roberto Ferreira dos Santos ORCID: https://orcid.org/0000-0003-0168-5286 Universidade do Porto, Portugal Universidade Salgado de Oliveira, Brasil E-mail: rob.fersantos1949@gmail.com

\begin{abstract}
Resumo
Este ensaio objetiva apresentar os pontos que determinaram a reconceptualização da Educação Física no contexto luso-brasileiro. Na perspectiva portuguesa, a década de sessenta marca o processo de transformação da Educação Física tradicional. Nesse enquadramento, observa-se que a necessidade de mudança foi potencializada pelo discurso científico e, indiscutivelmente, pela ascensão do Desporto na ocasião. No contexto brasileiro, nota-se que a década de oitenta é o marco do processo de escolarização do Esporte. Nomeadamente, é nessa fase da história que o discurso esportivista perde espaço para as concepções pedagógicas críticas que porventura procuram aproximar a Educação Física escolar do viés sociocultural. Assim sendo, constata-se que existe uma curta "curva de civilização" que distingue o discurso e as linhas paradigmáticas dos países em destaque. Há, além disso, fortes indícios que sinalizam que os embrolhos sociopolíticos, e todo um conjunto de práticas extraescolares, influenciam diretamente ou indiretamente à dimensão Educação Física, sobretudo no contexto brasileiro. Não obstante, percebe-se que, independentemente da linha paradigmática assumida, do contexto, precisamente, fundar e dignificar a profissão sempre foi (ainda é) o maior dos desafios! A complexidade está em preservar a legitimidade, a autenticidade da própria área. Desejo que requer lutas e intervenções em variadas dimensões. Não bastando apenas uma nova autocompreensão.
\end{abstract}

Palavras-chave: Reconceptualização da Educação Física; Dissemelhança epistêmica; Comunidade científica; Portugal; Brasil.

\begin{abstract}
This essay aims to present the points that determined the reconceptualization of Physical Education in the PortugueseBrazilian context. From the Portuguese perspective, the 1960's marked the transformation process of the traditional Physical Education. In this context, it is observed that the need for change was enhanced by the scientific discourse and, unquestionably, by the rise of Sport at the time. In the Brazilian context, it is noted that the 1980's is the milestone in the Sport schooling process. Namely, it is at this stage of history that the sports discourse loses space for critical pedagogical conceptions that possibly seek to bring Physical Education closer to the sociocultural bias.
\end{abstract}


Therefore, it is found that there is a short "civilization curve" that distinguishes the discourse and paradigmatic lines of the highlighted countries. There is, in addition, strong evidence that indicates that sociopolitical issues, and a whole set of extracurricular practices, directly or indirectly, influence the Physical Education dimension, especially in the Brazilian context. Nevertheless, it is perceived that, regardless of the paradigmatic line assumed, of the context, precisely, founding and dignifying the profession has always been (still is) the greatest challenge! The complexity is in preserving the legitimacy, the authenticity of the area itself. A desire that requires struggles and interventions on various dimensions. Only a new self-understanding is not enough.

Keywords: Reconceptualization of Physical Education; Epistemic dissimilarity; Scientific community; Portugal; Brazil.

\section{Resumen}

Este ensayo tiene como objetivo presentar los puntos que determinaron la reconceptualización de la Educación Física en el contexto portugués-brasileño. Desde una perspectiva portuguesa, los años sesenta marcaron el proceso de transformación de la Educación Física tradicional. En este contexto, se observa que la necesidad de cambio se vio reforzada por el discurso científico y, indiscutiblemente, por el auge del Deporte en su momento. En el contexto brasileño, se observa que la década de los ochenta es el hito en el proceso de escolarización en el Deporte. Es decir, es en esta etapa de la historia que el discurso deportivo pierde espacio ante concepciones pedagógicas críticas que quizás buscan acercar la Educación Física en la escuela al sesgo sociocultural. Por tanto, parece que existe una pequeña “curva de civilización” que distingue las líneas discursivas y paradigmáticas de los países destacados. Además, existe una fuerte evidencia que indica que cuestiones sociopolíticas, y todo un conjunto de prácticas extracurriculares, influyen directa o indirectamente en la dimensión de Educación Física, especialmente en el contexto brasileño. Sin embargo, está claro que, independientemente de la línea de paradigma que se adopte, el contexto, precisamente, fundar y dignificar la profesión siempre ha sido (¡sigue siendo) el mayor desafío! La complejidad radica en preservar la legitimidad, la autenticidad del propio territorio. Un deseo que requiere luchas e intervenciones en diversas dimensiones. Una nueva autocomprensión no es suficiente.

Palabras clave: Reconceptualización de la Educación Física; Disimilitud epistémica; Comunidad científica; Portugal; Brasil.

\section{O Contexto Português}

Zélia Matos (2004), sob esse prisma, apresenta os pontos que determinaram a reconceptualização da Educação Física (EF) em terras lusitanas. A comunidade científica portuguesa - no bojo dos movimentos internacionais - buscava, como ela mesma descreve, "uma nova auto-compreensão" (Matos, 2004, p. 255) quanto à fundamentação teórica que justificava o campo científico português na década de sessenta. Isto equivale a dizer que as Ciências da Motricidade Humana, as Ciências do Desporto e o conjunto de "sub-disciplinas" que delas provêm, identificam a curta "curva de civilização" (Elias, 1939) referente à cientificação da disciplina em questão. Sobretudo, as “teias de interdependência" (Elias, 1999) que conduziram Portugal, mesmo que tardiamente, a implementar o processo de transformação da Educação Física tradicional.

Com base neste quadro de referência, pode-se, portanto, interpretar que a designação tradicional da Educação Física perdia espaço junto aos movimentos internacionais e à comunidade científica portuguesa. Concomitantemente e em consequência disso, constituía-se, então, uma demanda social extraescolar que colocava em dúvida a capacidade de resposta da Educação Física tradicional, isso é, da Teoria da Educação Física. Sob esse enfoque, Zélia Matos (2004), no intento de forjar o sentimento que pairava no ar àquela altura, emite a seguinte constatação: "Os pontos de vista restritivos da Teoria da Educação Física afastam-na da realidade de uma forma significativa." (p. 253). E mais: "Existe a consciência generalizada de que a tradicional Educação Física está obsoleta e não é um termo apropriado para definir toda a “área” de estudo.” (ibidem, grifo da autora).

Sendo assim, pode-se concluir que, diante dessa conjuntura, a necessidade de mudança foi potencializada pelo discurso científico e, indiscutivelmente, pela ascensão do Desporto na ocasião, visto que o termo Educação Física era e ainda é - diferentemente do Brasil - uma dimensão estritamente escolar à luz dos teóricos portugueses. Nesse ínterim, as demandas sociais, as discussões acerca do corpo, as reflexões no tocante à exercitação corporal geral e à carência de trabalhos teóricocientíficos foi que, efetivamente, impulsionaram a comunidade acadêmica portuguesa a almejar uma nova designação, um novo sintagma, um núcleo comum. Como dá a entender Zélia Matos (2004), o que estava em jogo, àquela época, sobrepujava a 
simples readequação semiótica dos termos. A luta era por legitimidade, autenticidade da própria Educação Física, da própria área.

No período que compreende o processo de reconceptualização do conhecimento tradicional da Teoria da Educação Física em terras lusitanas, Lisboa adota o mote da Ciência da Motricidade Humana, em virtude dos seus teóricos optarem por enquadrar a Educação Física tradicional no escopo acientífico. Ao passo que Porto, no que lhe concerne, substitui o termo tradicional pelo sintagma Ciência do Desporto, uma vez que os teóricos portuenses entendiam que a academia, na ocasião, necessitava de um termo integrador de toda a área. O que permite uma melhor compreensão, hoje, do percurso da EF no ensino superior português e da relevância tanto da Universidade de Lisboa quanto da Universidade do Porto no que tange ao processo de cientificação da área e ao desenvolvimento de uma nova designação (Matos, 2004; Matos, 2006).

A Universidade de Lisboa, no correr da sua existência, no tocante à área de EF, ostenta três denominações medulares, a saber: Instituto Nacional de Educação Física; Instituto Superior de Educação Física de Lisboa; e a contemporânea designação que legitima/legaliza a Faculdade de Motricidade Humana da Universidade de Lisboa. Já a Universidade do Porto retrata o percurso sócio-histórico da área de Educação Física portuguesa a partir das seguintes denominações: Instituto Superior de Educação Física do Porto; Faculdade de Ciências do Desporto e de Educação Física da Universidade do Porto; e a vigente designação que legitima/legaliza a Faculdade de Desporto da Universidade do Porto (Portugal, 1975; Sérgio, 1989; Matos, 1999; Graça, 2015).

É preciso salientar que desde a década de setenta, decênio que marca a entrada da EF na universidade portuguesa, ambas as instituições vêm contribuindo na edificação de um corpo de conhecimento científico que visa, independentemente da linha paradigmática assumida, a fundar e a dignificar a profissão. Especificamente no trato da dissemelhança epistêmica, observa-se que a Faculdade de Motricidade Humana da Universidade de Lisboa, embebida pela imaginação epistemológica do professor Manuel Sérgio, encontra na "Educação Motora" o mote que melhor traduz o ramo pedagógico da Ciência da Motricidade Humana. Em contrapartida, a Faculdade de Desporto da Universidade do Porto, sob a égide epistemológica do professor Jorge Bento, embasa na "Pedagogia do Desporto" o conjunto de valores que distingue o ramo pedagógico da Ciência do Desporto (Sérgio, 1994; Matos, 1999; Bento, 2006; Mesquita \& Bento, 2014).

Por falar nos ramos pedagógicos que edificam o corpo científico das instituições e, consequentemente, dos teóricos, é bom deixar claro que o conceito anglo-saxónico de Desporto (Human Movement Science and Kinesiology), defendido por Manuel Sérgio, é restritivo quando comparado com a concepção europeia (Sportwissenschaft) perfilhada por Jorge Bento. Todavia, importa evidenciar que o campo epistemológico da Motricidade Humana é, por natureza, mais abrangente, em razão da pretensão de investigar todo o movimento originário do Homem. Entretanto, no momento da revisão do estado da arte, apresenta-se um ponto de convergência que sugestiona o genuíno objeto de estudo: a transcendência do corpo-alma-espírito (Sérgio, 1994; Matos, 1999; Bento, 2006; Matos \& Graça, 2016).

Portanto, diante disso, estima-se que não houve propriamente rivalidade, mas discursos paralelos que nunca se refutaram mutuamente. Os pensamentos, por certo, não são coincidentes, mas podem apontar - se assim entendidos - para a afluência imperativa de todo o processo de reconceptualização do conhecimento tradicional da Teoria da Educação Física em terras lusitanas: a necessidade do ser humano reinventar-se. Manuel Sérgio, com maior audiência no Brasil - fruto da tendência antidesportiva espalhada na comunidade intelectual da Educação Física brasileira - exprimiu essa inevitabilidade no paradigma da Motricidade Humana, ao passo que Jorge Bento, o pedagogo do Desporto, expressou nas Ciências do Desporto a valência intrínseca do "Homem-Todo" (Sérgio, 1994; Matos, 1999; Sérgio, 2003; Bento \& Bento, 2010; Matos \& Graça, 2016; Bento, 2017).

Nesse panorama, nota-se que é inegável a contribuição dos teóricos. Manuel Sérgio, a título de exemplo, ortografou uma série de obras, dentre as quais as de maior expressão são: "Educação física, ou, Ciência da motricidade humana?"; 
"Motricidade Humana - Contribuições para Um Paradigma Emergente"; e o livro "Um Corte Epistemológico. Da educação física à motricidade humana". Jorge Bento, verbi gratia, concebeu uma produção literária vultosa, na qual os manuscritos repercutem as discussões que permearam as décadas de oitenta e noventa, como se vê nas obras: "Desporto — < Matéria >> de Ensino"; "Planeamento e avaliação em educação física"; e o livro "O Outro Lado do Desporto. Vivências e reflexões pedagógicas" (Sérgio, 1989; Sérgio, 1994; Sérgio, 1999; Bento, 1987a; Bento, 1987b; Bento, 1995; Matos, 1999).

Este arcabouço teórico, relacionado com os manuscritos dos professores António Marques ("Desenvolvimento da capacidade de prestação de resistência: estudo aplicado em crianças e jovens do $5^{\circ}$ ao $9^{\circ}$ ano de escolaridade da região do grande Porto"); Francisco Sobral (“Estado de crescimento e aptidão física na população escolar dos Açores”); Vítor da Fonseca ("Contributo para o estudo da génese da Psicomotricidade”); e outros, retratam o passado recente da EF portuguesa. Aliás, muito do que se discute no espaço lusófono e fora dele - inerente à área - tem como base o escopo teórico-prático do Treino Desportivo de António Marques, a concepção global da Cineantropometria de Francisco Sobral e a abordagem pluridimensional da psicomotricidade pautada pelo professor Vítor da Fonseca (Marques, 1988; Sobral, 1989; Fonseca, 1976; Matos, 2004).

Particularmente, no campo da formação inicial de professores em Educação Física, verifica-se que a literacia portuguesa, diante do teor simbólico da virada do milênio, expôs a urgência de se detectar as competências necessárias para o pleno desenvolvimento da educação (escolarização) pelo corpo (Onofre, 1996; Costa, 1996; Queirós, 2014; Batista \& Pereira, 2014; Costa et al., 2014). Paralelamente a este efeito, observa-se ainda que os teóricos portugueses estavam movidos a combater a visão utilitarista/redutora da disciplina, confrontando assim a agenda neoliberal que desde os idos dos anos dois mil vem deturpando os princípios edificantes do conteúdo EF e a incumbência tradicional da instituição escola em escala mundial, salvo raras exceções (Morin, 2013; Bauman, 2013; UNESCO, 2015; Batista \& Queirós, 2015; Bento, 2017).

Consequentemente, o número de manuscritos que procuravam repercutir a necessidade de se repensar o papel da Educação Física, do Desporto, do professor de EF em especial, é o reflexo desse axioma. Entre as propostas que demarcaram esse período, figuram as que intercediam a favor da recolocação da aprendizagem como mote primordial do conteúdo EF, as que preconizavam o ensino dos jogos desportivos no âmbito escolar, bem como as que reivindicavam a reconstrução da identidade profissional do professor de EF. Ou seja, indícios que reverberam o processo de readequação da formação inicial e indubitavelmente evidenciam alguns dos desafios que inquietavam (e ainda inquietam) os teóricos lusitanos, no caso particular da escola e as suas configurações (Batista \& Queirós, 2015; Guilherme, 2015; Batista et al., 2014).

Depreende-se, então, que os teóricos portugueses, nomeadamente os afiliados à área da Educação Física, andam intrigados com interrogações que relativamente os aproximam dos desafios que assombram a educação (escolarização) em terras brasileiras. Nesta conformidade, Paula Batista e Paula Queirós (2015), na intenção de conduzir uma reflexão sobre o momento atual da disciplina, questionam: “Como é vista a Educação Física?” (p. 33). Jorge Bento (2017), apreensivo com os caminhos que a sociedade vem trilhando, indaga: "Será possível legitimar a existência escolar da Educação Física e do Desporto, como a de qualquer outra área, numa sociedade e numa era que se afastam manifestamente de um entendimento único da educação e que cultivam um conceito difuso do desporto e do seu sentido?" (Bento, 2017, p. 29, grifo do autor).

Nessa linha de raciocínio, José Sarmento, Flávia Bastos e Carla Luguetti (2014), debatendo acerca das complexidades que envolvem o Desporto, interpelam: “Que elemento privilegiar na sua apresentação em contexto escolar?” (p. 330). Amândio Graça (2015), versando sobre as tendências que abrangem o discurso pedagógico, interroga: "Educação Física, por quê e para quê?” (p. 15). Zélia Matos (2014), dialogando a respeito dos pormenores que teoricamente descortinam a Educação Física portuguesa, pergunta: “Que objetivos pedagógicos devem orientar uma boa educação desportivo-motora?” (p. 177, grifo da autora). Fernando Cardoso (2014), abordando fenômenos interessantes no tocante deste ensaio, inquire: “Através de que 
processos os professores conseguem chegar nos alunos, que alcance poderá ter esse apoio e que resultados podem ser esperados?" (p. 6).

Interrogações que, nessa fase conclusiva do debate, explicitam o passado recente da Educação Física à luz dos teóricos portugueses. O escopo teórico apresentado mapeia, em tese, o conjunto de valores das instituições e distingue, por conseguinte, a idiossincrasia dos agentes lusitanos em interação. Não é de se estranhar, portanto, que os contornos da 'legitimação' da EF, como disciplina integrante de uma escola que se assume como instituição social no âmbito de uma sociedade democrática, assim como a expressão cultural das concepções, dos currículos e das práticas dos professores, reflita o passado mais remoto, o passado recente e o tempo presente do conteúdo em terras lusitanas. Afinal, “[...] uma nova compreensão do passado produz simultaneamente uma nova perspectiva do futuro que por sua vez se torna num impulso para a vida intelectual e social.” (Borralho, 1997, p. 417).

\section{O Contexto Brasileiro}

A Educação Física à luz dos teóricos brasileiros - independentemente de consenso - está associada à grande área das Ciências da Saúde. Nessa perspectiva, a nomenclatura em questão não abrange única e exclusivamente o "campo" da escola, dado que, no Brasil, diferentemente de Portugal, a terminologia Educação Física escolar (EFe) é que fundamenta, institui e engloba formalmente a disciplina. Dessa forma, sendo a Educação Física uma das "configurações" da área da saúde, o vocábulo escolar é que determina o "campo" de intervenção do conteúdo. Em linhas gerais, é o vocábulo escolar que define a intencionalidade da Educação Física quanto à ação educativa da escola (Elias, 1999; Bourdieu, 2003).

Há duas ideias significativas nesse parecer. A primeira, de modo a dar ênfase aos aspectos terminológicos da disciplina em voga, expressa que a Educação Física à luz dos teóricos portugueses assume e incorpora o "campo" da escola. A segunda, de forma complementar e no intuito de evidenciar as nuances que emergem das "configurações" em destaque, expressa que a Educação Física em terras lusitanas usufrui das potencialidades do Desporto a ponto de justificá-lo como matéria de ensino; enquanto no Brasil o Desporto (leia-se: Esporte) não detém tamanha abrangência, já que ao longo do tempo as suas práticas culturais vêm sendo escolarizadas, atribuindo códigos próprios em torno da autonomia pedagógica da escola, sobretudo no que tange ao ensino da EFe em particular (Elias, 1999; Bourdieu, 2003; Vago, 1996; Bento, 2017).

Nesse enquadramento, a década de oitenta é o marco do processo de escolarização do Esporte em terras brasileiras. Nomeadamente, é nessa fase da história que o discurso esportivista (mecanicista, tecnicista e tradicional) perde espaço para as concepções pedagógicas críticas que porventura procuram aproximar a Educação Física escolar do viés sociocultural, contestando assim a ideologização do Esporte, a narrativa de cariz estritamente biologicista e as correntes higienistas, militaristas e as suas ramificações. Nesse caso, pode-se dizer, com base nesses pressupostos, que o novo panorama políticosocial, o processo de automação da mão de obra e a valorização dos conhecimentos produzidos pela ciência dinamizaram o surgimento de novos movimentos na esfera da Educação de maneira geral e no âmbito da Educação Física escolar de forma específica (Ghiraldelli Junior, 1991; Soares et al., 1992; Darido, 2003).

$\mathrm{Na}$ esfera da Educação, de maneira geral, a década de oitenta configura o período de ascensão da "Pedagogia progressista" (libertadora, libertária e crítico-social dos conteúdos), ainda que, na prática, as ideias de cunho Liberal (tradicional, renovada progressista, renovada não-diretiva e tecnicista) permanecessem praticamente inalteradas. Nesse ínterim, a Constituição de 1988 é vista por uma gama de teóricos como o divisor de águas no que se refere à reestruturação paradigmática da educação brasileira, uma vez que o documento estabelece uma série de deveres e direitos (sociais e individuais) que distanciam a instituição escola, ao menos ao nível do discurso, das "Teorias não-críticas" da educação, indo ao encontro dos preceitos que regem a "Pedagogia progressista" e as suas inúmeras classificações (Brasil, 1988; Libâneo, 1990; Saviani, 1991; Luckesi, 1994). 
No âmbito da Educação Física escolar, de forma específica, a década de oitenta configura o período de ascensão das abordagens, das tendências e concepções pedagógicas. Em razão disso, Suraya Darido (2003) destaca a abordagem "Desenvolvimentista", a abordagem "Construtivista-Interacionista" e a "Crítico-Superadora" como as principais tendências pedagógicas da Educação Física escolar a contar da década de oitenta. De acordo com a teórica, as obras mais representativas dessas abordagens são de autoria do professor Go Tani et al. (1988), "Educação Física escolar: fundamentos de uma abordagem desenvolvimentista"; João Batista Freire (1989), "Educação de corpo inteiro: teoria e prática da educação física" e a obra de Carmem Lúcia Soares et al. (1992), "Metodologia do ensino de Educação Física”, respectivamente (Darido, 2003).

Castellani Filho (1999), em sua tese de doutoramento intitulada "A Educação Física no sistema educacional brasileiro: percurso, paradoxos e perspectivas", desenvolve um construto fundamentado em um conjunto de linhas epistemológicas. Entre as perspectivas que o teórico emprega, estão as teorias não propositivas (abordagem Fenomenológica, abordagem "Sociológica" e a abordagem "Cultural") e as teorias propositivas, em que se destacam as teorias não sistematizadas (Concepção Desenvolvimentista, Concepção Construtivista, Educação Física "Plural”, Concepção de "Aulas Abertas" e a Concepção Crítico-Emancipatória). Nessa disposição, o teórico ainda destaca as teorias propositivas sistematizadas, representadas pelas Concepções da Aptidão Física e a Crítico-Superadora (ibidem).

Valter Bracht (1999), no livro "Educação física \& ciência: cenas de um casamento (in)feliz", mapeia as concepções apoiado em três expressões-chave. No âmbito da biologia, a expressão "atividade física" ("atividades físico-esportivas e recreativas") está diretamente concatenada à ideia de que o propositivo atribuído à Educação Física é o de colaborar para o desenvolvimento da aptidão física. No campo da psicologia do desenvolvimento, a expressão "movimento humano" ("movimento corporal humano", "motricidade humana" e "movimento humano consciente") está diretamente atrelada à compreensão da Educação Física como um dos meios de favorecer o desenvolvimento integral da criança. Enquanto no plano da cultura, a expressão "cultura corporal" ("cultura corporal de movimento" e "cultura de movimento") está diretamente associada à ressignificação do objeto da Educação Física (Bracht, 1999).

Feita essa demarcação, é importante destacar - independentemente da linha epistemológica assumida - algumas das questões que mobilizaram a comunidade acadêmica da Educação Física nesse espaço de tempo que compreende as décadas de oitenta e noventa: i) influência dos diversos ramos do conhecimento científico em escala global; ii) insurgência dos primeiros movimentos na esfera da Educação brasileira em escala nacional; iii) ausência de reflexões e justificativas convincentes a respeito da função e do sentido da disciplina; iv) incerteza dos objetivos concretos no tocante ao conteúdo; v) carência de referenciais específicos no que tange a definição de uma identidade própria para o corpo do conhecimento da Educação Física (Soares, 1986; Bracht, 1989; Medina, 1990; Darido, 2003; Farinatti \& Ferreira, 2006).

Diante desse quadro, para uma melhor compreensão dessas questões, faz-se necessário evidenciar uma série de interrogações que de certa forma evocam o sentimento que pairava no ar àquela altura. No horizonte filosófico crítico, João Medina (1990), em tom provocativo, questiona: "O que deve ser renovado ou transformado na Educação Física? Como renovar ou transformar a Educação Física? E para que renová-la ou transformá-la?” (p. 72). No contexto da epistemologia da Educação Física, Valter Bracht (1999), a título de contextualização e exemplo, indaga: “A EF é uma ciência ou uma disciplina científica? Deve a EF almejar/pretender ser uma ciência? É essa uma reivindicação legítima? Essa pretensão é orginária do interior da própria EF ou de "fora" dela?" (p. 27, grifo do autor).

Elenor Kunz (1995), na esteira desse debate, pergunta: “[...] como e com que objetivos os conhecimentos científicos (teorias) produzidos para a área da Educação Física se tornam conteúdos úteis às práticas pedagógicas da Educação Física Escolar?” (p. 48, grifo do autor). Faria Junior et al. (1996), receosos com as questões inerentes à regulamentação da profissão, interpelam: "A existência de órgãos reguladores da profissão e a existência de um código de ética profissional contribuiriam para consolidar a educação física como uma profissão?” (p. 269, grifo dos autores). Tarcísio Vago (1996), debruçado sobre o 
liame esporte na escola-esporte da escola, interroga: "É impossível a escolarização do esporte, isto é, a produção de um “esporte da escola”, que seja uma prática da cultura escolar, com seus códigos próprios?” (p. 9, grifo do autor).

Por tudo isso, as décadas de oitenta e noventa marcaram o período de crise identitária da Educação Física em terras brasileiras. No início dos anos oitenta, data da primeira edição do livro "A educação fisisica cuida do corpo e... "mente”: bases para a renovação e transformação da educação física", João Medina (1983) deixa transparecer que a Educação Física, na figura dos seus agentes, precisava urgentemente entrar em crise. Dentro desse cenário e dessa ótica, Ghiraldelli Junior (1991), à guisa de ilustração, emprega o termo ebulição para descrever essa passagem de tempo. Segundo o teórico, desde o início dos anos oitenta havia "[...] núcleos empenhados na rediscussão de temas que [iam] desde a redefinição do papel da Educação Física na sociedade brasileira até questões ligadas às mudanças necessárias ao nível da prática efetiva nas quadras, ginásios e campos." (Ghiraldelli Junior, 1991, p. 15, grifo nosso).

Hajime Nozaki (2014), ao rememorar essa fase da história, declara que a partir "dos idos de 1980, a educação física brasileira assistiu a um intenso questionamento no que diz respeito à necessidade de uma discussão acerca da sua importância no plano social e político [...].” (p. 318). O teórico reforça esse argumento quando afirma que, do ponto de vista da produção do conhecimento, esse período ficou caracterizado pela "[...] reivindicação de um caráter pedagógico que pudesse trabalhar em favor de um projeto humano emancipador." (ibidem). Datam desse período, o livro "Educação Física no Brasil: a história que não se conta"; a tese de doutoramento "Educação Física brasileira: autores e atores da década de 80"; e o artigo "Mas afinal, o que é Educação Física?" (Castellani Filho, 1988; Daolio, 1997; Gaya, 1994).

Por sinal, o artigo do professor Adroaldo Gaya (1994), “Mas afinal, o que é Educação Física?”, é o primeiro de uma série de textos que acabaram por incitar o debate acadêmico na ocasião. No mesmo ano, Celi Taffarel e Micheli Escobar (1994) criticaram - de modo contundente - a imaginação epistemológica de Gaya no artigo "Mas, afinal, o que é Educação Física?: um exemplo do simplismo intelectual". No ano seguinte, Valter Bracht (1995, grifo do autor), no intuito de reexaminar a pergunta central do debate, escreveu o texto "Mas, afinal, o que estamos perguntando com a pergunta "o que é Educação Física". Na mesma revista, dando continuidade à polêmica, Silvino Santin (1995) e Ghiraldelli Junior (1995) encabeçaram os artigos "A respeito de comentários" e "A volta ao que parece simples" na devida ordem.

No bojo desse debate, Hugo Lovisolo (1995), incomodado com o tom desrespeitoso de Taffarel e Escobar, redigiu o texto "Mas, afinal, o que é Educação Física?: a favor da mediação e contra os radicalismos". Em conformidade com Lovisolo, Lamartine da Costa (1996) rebate as críticas de Taffarel e Escobar no artigo "Uma questão ainda sem resposta: o que é a Educação Física?". No mesmo volume, procurando relativizar a polêmica que se instaurou nos dois primeiros números da "Revista Movimento", Gabriel Palafox (1996) escreve o texto "O que é Educação Física? Uma abordagem curricular", onde evidencia a necessidade do professor de Educação Física posicionar-se na sua área de atuação. Já que na perspectiva de Palafox (ibidem), o professor de Educação Física não é meramente um "agente pedagógico: ele é um agente políticopedagógico que deve ser capacitado com bases filosóficas, científicas e pedagógicas suficientes para poder "dar conta" não somente de seu fazer restrito (aula) [...]." (p. 12, grifo do autor).

Nesse ínterim, nesse meio-tempo em que o debate de cunho político-partidário acirrou-se tanto na esfera da Educação, de maneira geral, quanto no âmbito da Educação Física escolar, de forma específica, deu-se a promulgação do Estatuto da Criança e do Adolescente (Brasil, 1990), houve a publicação da nova Lei de Diretrizes e Bases da Educação Nacional (Brasil, 1996), a apresentação dos Referenciais Curriculares Nacionais para a Educação Infantil (Brasil, 1998a), bem como a elaboração dos Parâmetros Curriculares Nacionais (PCNs). Estes, que no âmbito da Educação Física escolar, para os terceiros e quartos ciclos do ensino fundamental, trazem “[...] uma proposta que procura democratizar, humanizar e diversificar a prática pedagógica da área, buscando ampliar, de uma visão apenas biológica, para um trabalho que incorpore as dimensões afetivas, cognitivas e socioculturais dos alunos.” (Brasil, 1998b, p. 15). 
Nesse período, que compreende particularmente a década de noventa, os esforços na área educacional estavam voltados para a (re)organização, para a (re)estruturação do sistema de ensino. Na esfera da Educação, de maneira geral, as investidas buscavam a implementação de um currículo nacional comum, enquanto a narrativa da Educação Física escolar, de forma específica, girava em torno dos princípios que regem a cultura corporal de movimento e as suas interfaces. Nesse particular, faz-se necessário realçar que é nessa fase da história que as atividades rítmicas e expressivas; o conhecimento sobre o corpo; os esportes; os jogos; as lutas e as ginásticas ganharam relevância no campo da EFe em terras brasileiras (Brasil, 1996; Brasil 1998a; Brasil, 1998b; Carvalho Junior \& Osborne, 2018).

Sendo assim, é preciso ter claro que esse período, além de marcar a consolidação da cultura corporal de movimento, enfatiza em teoria a ascensão da educação crítica no âmbito da EFe. Valter Bracht (1999), no texto "A Prática Pedagógica da Educação Física: conhecimento e especificidade [1]", declara que a educação crítica no domínio da EFe "tem igual preocupação com a educação estética, com a educação da sensibilidade, o que significa dizer, "incorporação", não por via do discurso e, sim, por via das "práticas corporais" [...]." (p. 54, grifo do autor). De acordo com o teórico, essas práticas são constituídas por "normas e valores que orientam gostos, preferências, que junto com o entendimento racional, determinam a relação dos indivíduos com o mundo.” (Bracht, 1999, p. 54).

Por falar na relação dos indivíduos com o mundo, Suraya Darido et al. (2001) expuseram que a Educação, de maneira geral, e a Educação Física escolar, de forma específica, demandam que assuntos sociais emergentes sejam incorporados e questionados no dia a dia da escola "buscando um tratamento didático que contemple a sua complexidade e sua dinâmica, no sentido de contribuir com a aprendizagem, a reflexão e a formação do cidadão crítico." (p. 30). Para o alcance de tal preposição, os teóricos destacam o princípio da inclusão, as dimensões dos conteúdos e os temas transversais como as três vertentes "mais marcantes da proposta dos PCNs - área Educação Física [escolar], que representam aspectos relevantes a serem buscados dentro de um projeto de melhoria da qualidade das aulas [...]." (Darido et al., 2001, p. 30, grifo nosso).

Ainda segundo tal olhar, enfatizam que os Parâmetros Curriculares Nacionais, para os terceiros e quartos ciclos, ajudam a compreender a proposta de Educação Física cidadã, cuja concepção, tendo em vista os objetivos gerais para o ensino fundamental, visa à formação cidadã. Nesse caso, se assim entendido, os temas transversais teriam importância ímpar quanto à consolidação de tal objetivo, uma vez que os teóricos interpretam os temas (ética, saúde, meio ambiente, orientação sexual, pluralidade cultural, trabalho e consumo) como ruas, isto é, vias centrais do currículo escolar. Dessa forma, fica subentendido que toda disciplina, quer seja na dimensão teórica, quer seja na dimensão prática, pode (deve) cruzar esses ou qualquer outro tema que se revele pertinente num determinado contexto (Darido et al., 2001).

A propósito, o contexto - a desigualdade social - é o grande mote da Educação em meio à contemporaneidade (Morin, 2013; Bauman, 2013; PNUD, 2014; MEC, 2014; UNESCO, 2015). No caso do Brasil, essa constatação ganha contornos superlativos quando se vê um número significativo de pessoas residindo em aglomerados subnormais, ocupações irregulares e/ou comunidades conflagradas (IBGE, 2011). Maria Alves e Philip Evanson (2013), refletindo acerca desse fenômeno, conduzem o pensamento de que as favelas do século XXI seriam as senzalas de outrora. No caso do Rio de Janeiro em particular, os teóricos evidenciam que essa ideia de senzala atual "explica-se, em parte, porque os que moram no asfalto [classe média] tendem a ignorar a repressão e os assassinatos ocorridos próximo da região onde residem. E justamente o outro lado da moeda é a mentalidade daqueles que vivem na casa-grande [classe alta]." (Alves \& Evanson, 2013, p. 38-39, grifo nosso).

Pois tal como salientou Arnaldo Jabor, na parte introdutória do livro "Cidade Partida" de autoria do jornalista Zuenir Ventura (1994), o Rio de Janeiro dos anos cinquenta já aglomerava conflagrações que iriam, irremediavelmente, estourar nas décadas seguintes. De acordo com o cineasta, havia desde então duas cidades ou uma cidade partida, "mas a convivência

${ }^{[1]}$ Artigo originalmente publicado na Revista Paulista de Educação Física. Supl. 2, 1996, p. 23-8. 
amena, a obediência civil, a falta de antagonismos de classe e a despreocupação com os problemas sociais nem sempre deixavam perceber que havia um ovo de serpente chocando no paraíso." (ibidem, p. 6). Resumidamente, a sociedade civil organizada não deu conta (será?) do mal incubado que hodiernamente aflige tanto os que residem na "senzala atual" quanto os que vivem na "casa-grande" (Ventura, 1994; Alves \& Evanson, 2013).

Todo esse cenário faz pensar na importância da "educação crítica" num contexto tão conflagrado como o do Rio de Janeiro, por exemplo. Assumir isso, nessa fase conclusiva do debate, é compreender e atestar que a instituição escola, na figura dos seus agentes, é uma das poucas organizações governamentais que atende tanto os que residem na "senzala atual" quanto os que vivem na "casa-grande". O professor de EF, nesse sentido, muitas vezes tem ainda mais acesso a determinadas áreas da cidade, haja vista a instalação de projetos - esportivos - sociais, vilas olímpicas, academias ao ar livre e equipamentos esportivos em comunidades comumente dominadas por narcotraficantes e/ou grupos paramilitares (Ventura, 1994; Bracht, 1999; Alves \& Evanson, 2013; Santos \& Silva, 2018).

\section{Considerações Finais}

À luz do estado da arte, tecendo um paralelo entre o passado recente da Educação Física no contexto luso-brasileiro, vê-se que existe uma curta "curva de civilização" (Elias, 1939) que distingue o discurso e as linhas paradigmáticas dos países em destaque. Há, além disso, fortes indícios que sinalizam que os embrolhos sociopolíticos e todo um conjunto de práticas extraescolares influenciam direta ou indiretamente a dimensão EF, sobretudo no contexto brasileiro. Por isso, devido à complexidade do fenômeno em apreço, entende-se que esgotar o que dele emerge ou extrair conclusões objetivas com base na argumentação alinhavada até aqui, seria um tanto quanto precipitado e ingênuo do ponto de vista teórico-epistemológico.

Não obstante, especificamente no contexto brasileiro, lançando mão da liberdade, do fluxo natural das ideias, da subjetividade característica de um ensaio-teórico, que é o caso em questão, observa-se que a ideologização, a politização em torno do Desporto, da Educação Física em particular, exerce uma influência deveras prejudicial para a área. Nessa lógica, tendo como parâmetros reflexivos acontecimentos hodiernos, no tocante à área em voga e às suas interfaces, verifica-se que, enquanto Portugal (na figura dos seus homens públicos) repensou os seus conceitos em relação à Educação Física, os 'governantes' brasileiros cogitaram retirar das grades curriculares do Ensino Médio os conteúdos de Artes, Educação Física, Filosofia e Sociologia.

Apesar disso, no caso de Portugal, o debate ultrapassou o campo escolar, dado que um número vultoso de portugueses rejeita a decisão da nota de EF voltar a contar para acesso à universidade. Os agentes empoderados pela invisibilidade característica da internet empregam argumentos que justificariam o conceito de "diferenciação social negativa" de Pierre Bourdieu (2007). A luta está, assim, indiretamente associada ao "capital simbólico" de cada cidadão, mas diretamente concatenada à vida acadêmica daqueles que por lá quiserem transitar. Isto é, uma "valência aberta" estaria a provocar certa instabilidade nas "formas simbólicas de dominação" e na "dinâmica de atração e de repulsão" que caracterizam a obra de Pierre Bourdieu (2012) e Norbert Elias (1999) em equivalência.

No caso do Brasil, a atitude dos políticos repercute a falta de sensibilidade com a res publica. O país sediou, num curto espaço de tempo, os Jogos Pan-Americanos Rio 2007; os Jogos Mundiais Militares de 2011; a Copa das Confederações da Federação Internacional de Futebol Associado (FIFA) de 2013; a Copa do Mundo FIFA de 2014; os Jogos Olímpicos Rio 2016. Cogitar, como resultado, uma medida dessa natureza, ao apagar das luzes da Paralimpíada Rio 2016, é no mínimo um desrespeito aos profissionais de Educação Física. Ou seja, as estruturas de poder e de dominação nem sequer tiveram a preocupação de esperar - como é dito no Brasil - baixar a poeira para virar as costas para o que antes era, se assim se pode dizer, a menina dos olhos dos homens públicos brasileiros.

Em síntese, na tentativa de compreender o passado recente da Educação Física no contexto luso-brasileiro, a favor de 
uma consideração que permita demarcar algumas impressões, percebe-se que, independentemente da linha paradigmática assumida, do contexto, precisamente, fundar e dignificar a profissão sempre foi (ainda é) o maior dos desafios! O problema não está em resguardar o cariz legítimo da disciplina, dado que o caráter legítimo é previsto em Lei como meio de salvaguardar o exercício profissional do professor de EF, especialmente a promoção prioritária do Desporto/Esporte educacional na esfera luso-brasileira. A complexidade está em preservar a legitimidade, a autenticidade da própria área. Desejo que requer lutas e intervenções em variadas dimensões. Não bastando apenas uma nova auto-compreensão.

\section{Referências}

Alves, M. H. M., \& Evanson, P. (2013). Vivendo no fogo cruzado: moradores de favela, traficantes de droga e violência policial no Rio de Janeiro. S.

Batista, P., Graça, A., \& Queirós, P. (2014). O estágio profissional na (re)construção da Identidade profissional em Educação Física. FADEUP.

Batista, P., \& Pereira, A. L. (2014). Uma Reflexão Acerca da Formação Superior de Profissionais de Educação Física: da Competência à Conquista de uma Identidade Profissional. In I. Mesquita., \& J. Bento. (Eds.), Professor de Educação Física: Fundar e dignificar a profissão (pp. 75-101). Porto: FADEUP.

Batista, P., \& Queirós, P. (2015). (Re)colocar a aprendizagem no centro da Educação Física. In R. Rolim., P. Batista., \& P. Queirós. (Eds.), Desafios renovados para a aprendizagem em Educação Física (pp. 29-43). FADEUP.

Bauman, Z. (2013). Sobre educação e juventude: conversas com Ricardo Mazzeo / Zygmunt Bauman. Tradução Carlos Alberto Medeiros. Rio de Janeiro: Zahar.

Bento, J. O. (1987a). Desporto $-<<$ Matéria $>>$ de Ensino. Editorial Caminho.

Bento, J. O. (1987b). Planeamento e avaliação em educação física. Livros Horizonte.

Bento, J. O. (1995). O Outro Lado do Desporto. Vivências e reflexões pedagógicas. Campo das Letras.

Bento, J. O. (2006). Da Pedagogia do Desporto. In G. Tani., J. O. Bento., \& R. D. S. Petersen. (Eds.), Pedagogia do desporto (pp. 26-40). Guanabara Koogan.

Bento, J. O., \& Bento, H. C. B. (2010). Desporto e Educação Física - acerca do ideal pedagógico. In J. O. Bento., G. Tani., \& A. Prista. (Eds.), Desporto e Educação Física em Português (pp. 13-35). Portugal: Multitema.

Bento, J. O. (2017). Em nome da Educação Física e do Desporto na escola: legitimação, considerações e orientações pedagógico-didáticas. Casa da Educação Física.

Borralho, M. J. (1997). O professor e o universo da estética. In M. F. Patrício. (Ed.), A Escola Cultural e os Valores (pp. 415-418). Porto Editora.

Bourdieu, P. (2003). Algumas propriedades dos campos. In P. Bourdieu (Ed.), Questões de Sociologia (pp. 119-126). Fim de Século - Edições, Sociedade Unipessoal, Lda.

Bourdieu, P. (2007). A distinção: crítica social do julgamento. Edusp; Zouk.

Bourdieu, P. (2012). O poder simbólico (16a ed.). Bertrand Brasil.

Bracht, V. (1989). Educação física: a busca da autonomia pedagógica. Revista da Educação Física, UEM, O(1), 28-33.

Bracht, V. (1995). Mas, afinal, o que estamos perguntando com a pergunta "o que é Educação Física". Revista Movimento, 2(2), I-VIII.

Bracht, V. (1999). Educação física \& ciência: cenas de um casamento (in)feliz. Ijuí: Editora Unijuí.

Brasil. (1988). Constituição da República Federativa do Brasil de 1988. http://www.planalto.gov.br/ccivil_03/Constituicao/Constituicao.htm

Brasil. (1990). Estatuto da Criança e do Adolescente. LEI Nº 8.069, DE 13 DE JULHO DE 1990. http://www.planalto.gov.br/ccivil_03/leis/18069.htm

Brasil. (1996). Lei 9.394, de 20 de dezembro de 1996, estabelece as diretrizes e bases da educação nacional. http://www.planalto.gov.br/ccivil_03/leis/L9394.htm

Brasil. (1998a). Ministério da Educação e do Desporto. Secretaria de Educação Fundamental. Referencial curricular nacional para a educação infantil. Brasília: MEC/SEF. http://portal.mec.gov.br/seb/arquivos/pdf/rcnei_vol1.pdf

Brasil. (1998b). Ministério da Educação e do Desporto. Secretaria de Educação Fundamental. Parâmetros curriculares nacionais terceiro e quarto ciclos do ensino fundamental: Educação Física. Brasília: MEC/SEF. http://portal.mec.gov.br/seb/arquivos/pdf/fisica.pdf

Cardoso, F. J. (2014). Gimnocerco - um exemplo de empoderamento, de excelência desportiva e de desenvolvimento de competências de vida. Porto: Fernando Cardoso. Dissertação de doutoramento apresentada à Faculdade de Desporto da Universidade do Porto.

Carvalho Junior, A. F. P. de., \& Osborne, R. (2018). Currículo: Conceitos, História e Educação Física escolar. In A. F. P. de Carvalho Junior., \& R. Osborne. (Eds.), Educação física escolar e questões curriculares (19-34). Appris. 
Castellani Filho, L. (1988). Educação Física no Brasil: a história que não se conta. Papirus.

Castellani Filho, L. (1999). A Educação Física no sistema educacional brasileiro: percurso, paradoxos e perspectivas. Lino Filho. Dissertação de doutoramento apresentada à Faculdade de Educação da Universidade Estadual de Campinas.

Costa, L. P. da. (1996). Uma questão ainda sem resposta: o que é a Educação Física? Revista Movimento, 3(4), I-X.

Costa, M., Batista, P., \& Graça, A. (2014). A formação inicial de professores de Educação Física em Portugal e sua relação com o Processo de Bolonha. In P. Batista., A. Graça., \& P. Queirós. (Eds.), O Estágio Profissional na (re)construção da identidade profissional em Educação Física (pp. 87-111). Porto: FADEUP.

Daolio, J. (1997). Educação Física brasileira: autores e atores da década de 80. Jocimar Daolio. Dissertação de doutoramento apresentada à Faculdade de Educação Física da Universidade Estadual de Campinas.

Darido, S. C. et al. (2001). A Educação Física, a Formação do Cidadão e os Parâmetros Curriculares Nacionais. Rev. paul. Educ. Fís, 15(1), 17-32.

Darido, S. C. (2003). Educação Física na escola: questões e reflexões. Guanabara Koogan.

Elias, N. (1939). O Processo civilizador. Volume 1: Uma história dos CostumesJorge Zahar.

Elias, N. (1999). Introdução à sociologia. Edições 70.

Faria Junior, A. G. de. et al. (1996). O velho problema da regulamentação. Contribuições críticas à sua discussão. Revista Brasileira de Ciências do Esporte, 17(3), 266-272.

Farinatti, P. de T. V., \& Ferreira, M. S. (2006). Saúde, promoção da saúde e educação física: conceitos, princípios e aplicações. EdUERJ.

Fonseca, V. da. (1976). Contributo para o estudo da génese da psicomotricidade. Editorial notícias.

Gaya, A. (1994). Mas afinal, o que é Educação Física? Revista Movimento, 1(1), 29-34.

Ghiraldelli Junior, P. (1991). Educação Física Progressista. A Pedagogia Crítica-Social dos Conteúdos e a Educação Física Brasileira. Edições Loyola.

Ghiraldelli Junior, P. (1995). A volta ao que parece simples. Revista Movimento, 2(2), XV-XVII.

Graça, A. (2015). Formação do professor de educação física: evolução do quadro normativo. In R. Resende., A. Albuquerque \& A. R. Gomes. (Eds.), Formação e saberes em desporto, educação física e lazer (pp. 275-313). Visão e Contextos.

Guilherme, J. (2015). Um olhar sobre o ensino dos jogos desportivos em contexto escolar. In R. Rolim., P. Batista., \& P. Queirós. (Eds.), Desafios renovados para a aprendizagem em Educação Física (pp. 107-124). FADEUP.

IBGE. (2011). Censo 2010: Aglomerados Subnormais $\quad-\quad$ Informações $\quad$ Territoriais. https://ww2.ibge.gov.br/home/presidencia/noticias/imprensa/ppts/00000015164811202013480105748802.pdf

Kunz, E. (1995). A relação teoria/prática no ensino/pesquisa da educação física. Motrivivência, 7(8), 46-54.

Libâneo, J. C. (1990). Democratização da Escola Pública. A Pedagogia Crítico-Social dos Conteúdos. Loyola.

Lovisolo, H. (1995). Mas, afinal, o que é Educação Física? a favor da mediação e contra os radicalismos. Revista Movimento, 2(2), XVIII-XXIV.

Luckesi, C. C. (1994). Filosofia da Educação. Cortez.

Marques, A. T. (1988). Desenvolvimento da capacidade de prestação de resistência: estudo aplicado em crianças e jovens do $5^{\circ}$ ao $9^{\circ}$ ano de escolaridade da região do grande Porto. Porto: António Marques. Dissertação de doutoramento apresentada à Faculdade de Ciências do Desporto e de Educação Física da Universidade do Porto.

Matos, Z. (1999). Estudo da Pedagogia do Desporto em Portugal. Contributo para a sua compreensão. Coimbra: Zélia Matos. Dissertação de doutoramento apresentada à Faculdade de Ciências do Desporto e Educação Física da Universidade de Coimbra.

Matos, Z. (2004). Pedagogia do Desporto: novas questões velhos problemas. In E. Lebre., \& J. Bento. (Eds.), Professor de Educação Física. Ofícios da Profissão (pp. 251-284). FCDEFUP.

Matos, Z. (2006). Contributos para a Compreensão da Pedagogia do Desporto. In G. Tani., J. O. Bento., \& R. D. S. Petersen. (Eds.), Pedagogia do desporto (pp. 154-184). Guanabara Koogan.

Matos, Z. (2014). Educação Física na Escola: da Necessidade da Formação aos Objetivos e Conteúdos Formativos. In I. Mesquita., \& J. O. Bento. (Eds.), Professor de Educação Física: Fundar e dignificar a profissão (pp. 157-190). FADEUP.

Matos, Z., \& Graça, A. (2016). Jorge Olímpio Bento, o pedagogo do desporto. Revista Portuguesa de Ciências do Desporto, 4(S1), 52-64.

MEC. (2014). Pesquisa Nacional por Amostras de Domicílios do IBGE (PNAD, população). http://portal.mec.gov.br/component/tags/tag/32962\#footer

Medina, J. P. S. (1983). A educação física cuida do corpo e... “mente”: bases para a renovação e transformação da educação física. Papirus.

Medina, J. P. S. (1990). A educação física cuida do corpo e... “mente”: bases para a renovação e transformação da educação física (9a ed.). Papirus.

Mesquita, I., \& Bento, Jorge. (2014). Professor de Educação Física: Fundar e dignificar a profissão. FADEUP. 
Research, Society and Development, v. 10, n. 16, e463101624017, 2021

(CC BY 4.0) | ISSN 2525-3409 | DOI: http://dx.doi.org/10.33448/rsd-v10i16.24017

Morin, E. (2013). A via para o futuro da humanidade / Edgar Morin. Tradução Edgard de Assis Carvalho, Mariza Perassi Bosco. Bertrand.

Nozaki, H. T. (2014). Crise do Capital e Crise de Identidade da Educação Física Brasileira: Mediações no mundo do trabalho. In A. Faria Junior., J. O. Bento., R. F. dos Santos., \& C. A. Boschi. (Eds.), Educação Física e Desporto: Relação Brasil Portugal (pp. 315-344). Casa da Educação Física.

Onofre, M. S. (1996). A Supervisão Pedagógica no Contexto da Formação Didáctica em Educação Física. In F. C. da. Costa et al. (Eds.), Formação de Professores em Educação Física. Concepções, Investigação, Prática (pp. 75-118). Serviço de Edições Cruz-Quebrada.

Palafox, G. H. M. (1996). O que é Educação Física? Uma abordagem curricular. Revista Movimento, 3(4), XI-XIV.

PNUD. (2014). Sustentar o Progresso Humano: Reduzir as Vulnerabilidades e Reforçar a Resiliência. http://hdr.undp.org/sites/default/files/hdr2014_pt_web.pdf

Portugal. (1975). Diário do Governo n. ${ }^{\circ}$ 279/1975, Série I de 1975-12-03. Ministério da Educação e Investigação Científica. Instituto Superior de Educação $\begin{array}{lllllll}\text { Física } & \text { (Decreto-Lei } \quad{ }^{\circ}{ }^{\circ} \quad 675 / 75, \quad \text { de } & \text { de } & \text { dezembro). } & \text { https://dre.pt/web/guest/pesquisa/- }\end{array}$ /search/309534/details/normal?q=educa\%C3\%A7\%C3\%A3o+f\%C3\%ADsica

Queirós, P. M. L. (2014). Profissionalidade Docente: Importância das Questões Deontológicas na Formação Inicial de Profissionais [de Educação Física e Desporto]. In I. Mesquita., \& J. O. Bento. (Eds.), Professor de Educação Física: Fundar e dignificar a profissão (pp. 55-73). FADEUP.

Santin, S. (1995). A respeito de comentários. Revista Movimento, 2(2), IX-XIV.

Santos, L. C., \& Silva, C. A. F. da. (2018). Educação física, infância e comunidades conflagradas. In M. Murad., R. F. dos. Santos., \& C. A. F. da. Silva. (Eds.), Escolas, violências e educação física (87-110). Jaguatirica.

Sarmento, J. P., Bastos, F. da C., \& Luguetti, C. N. (2014). A Sustentabilidade dos Sistemas Desportivos e o Desporto na Escola. In I. Mesquita., \& J. Bento. (Eds.), Professor de Educação Física: Fundar e dignificar a profissão (pp. 323-347). FADEUP.

Saviani, D. (1991). Pedagogia histórico-crítica: primeiras aproximações. Cortez.

Sérgio, M. (1989). Educação física, ou, Ciência da motricidade humana? Papirus.

Sérgio, M. (1994). Motricidade Humana - Contribuições para Um Paradigma Emergente. Instituto Piaget.

Sérgio, M. (1999). Um Corte Epistemológico. Da educação física à motricidade humana. Instituto Piaget.

Sérgio, M. (2003). Para uma nova dimensão do desporto. Instituto Piaget.

Soares, C. L. (1986). A Educação física no ensino de $1^{\circ}$ grau: do acessório ao essencial. Revista Brasileira de Ciências do Esporte, 3(7), 89-92.

Soares, C. L. et al. (1992). Metodologia do Ensino de Educação Física. Cortez.

Sobral, F. (1989). Estado de crescimento e aptidão física na população escolar dos Açores. ESEF/UTL/DREFD/SREC/RAA.

Taffarel, C. N. Z., \& Escobar, M. O. (1994). Mas, afinal, o que é Educação Física?: um exemplo do simplismo intelectual. Revista Movimento, 1(1), 35-40. Tani, G. et al. (1988). Educação Física escolar: fundamentos de uma abordagem desenvolvimentista. EPU/EDUSP.

UNESCO. (2015). Relatório de Monitoramento Global de EPT. Educação para todos 2000-2015: Progressos e Desafios. http://unesdoc.unesco.org/images/0023/002325/232565por.pdf

Vago, T. M. (1996). O "esporte na escola" e o "esporte da escola": da negação radical para uma relação de tensão permanente. Um diálogo com Valter Bracht. Revista Movimento, 3(5), 4-17.

Ventura, Z. (1994). Cidade Partida. Companhia das Letras. 